\title{
Educação permanente em saúde: uma revisão integrativa de literatura
}

\author{
Permanent health education: an integrative review of literature \\ Educación permanente en salud: una revisión integradora de la literatura
}

\section{Resumo}

A Educação Permanente em Saúde (EPS) afirma-se como uma importante estratégia para mudança de práticas e realidades no trabalho em saúde. Fundamenta-se principalmente no desenvolvimento de espaços democráticos e na construção coletiva de conhecimentos, apoiados nas necessidades do trabalho e/ou da saúde dos usuários. Este estudo objetivou conhecer como tem sido abordada a temática da Educação Permanente em Saúde na literatura científica, de forma a conhecer os entendimentos, potencialidades e impasses relativos à EPS. Para tanto, utilizou-se da Revisão Integrativa, a qual permitiu uma sistematização concisa dos conhecimentos e dados obtidos de estudos empíricos e nãoempíricos sobre a temática em questão. Foi observada uma consonância entre os entendimentos presentes na literatura científica e os veiculados pelos documentos oficiais, entretanto compareceu certa dificuldade na distinção dos conceitos de EPS e Educação Continuada (EC). Em relação aos impasses decorrentes da EPS constatou-se dificuldades de ordem institucional, relativas aos processos de trabalho e formação em saúde no Brasil. A EPS destacou-se ainda como ferramenta viabilizadora de mudanças na organização do trabalho, nos modelos de assistência e concepções de saúde, permitindo ao trabalhador o desenvolvimento de autonomia e incremento às habilidades técnicas e relacionais. Palavras-chave: Formação profissional em saúde; Educação na saúde; Sistema Único de Saúde; Revisão.

\begin{abstract}
Permanent Health Education (PHE) asserts itself as an important strategy for changing practices and realities in health work. It is based mainly on the development of democratic spaces and on the collective construction of knowledge supported by the work and/or health needs of users. This study aimed to understand how the theme of Continuing Education in Health has been addressed in the scientific literature, in order to know the understandings, potentials and impasses related to PHE. For that, we used the Integrative Review, which allowed a concise systematization of knowledge and data obtained from empirical and non-empirical studies on the subject in question. A consonance was observed between the understandings present in the scientific literature and those conveyed by official documents, however there is a certain difficulty in distinguishing the concepts of PHE and Continuing Education (CE). Regarding the impasses resulting from PHE, difficulties of an institutional nature were found, related to the work processes and training in health in Brazil. PHE also stood out as a tool to enable changes in the organization of work, in care models and health concepts, allowing the worker to develop autonomy and increase technical and relational skills.
\end{abstract}

Keywords: Professional training in health; Health education; Health Unic System; Review.

\section{Resumen}

La Educación Permanente en Salud (EPS) es una estrategia importante para cambiar las prácticas y realidades en el trabajo de salud. Se basa principalmente en el desarrollo de espacios democráticos y en la construcción colectiva de conocimientos sustentados en las necesidades laborales y / o de salud de los usuarios. Este estudio tuvo como objetivo comprender cómo se ha abordado el tema de la Educación Permanente en Salud en la literatura científica, con el fin de conocer los entendimientos, potencialidades e impasses relacionados con la EPS. Para ello, se utilizó la Revisión Integrativa, que permitió una sistematización concisa de los conocimientos y datos obtenidos de estudios empíricos y no empíricos sobre el tema en cuestión. Se observó una consonancia entre los entendimientos presentes en la literatura científica y los transmitidos por los documentos oficiales, sin embargo existe cierta dificultad para distinguir los 
conceptos de EPS y Educación Continua (CE). En cuanto a los impasses resultantes de la EPS, se encontraron dificultades de carácter institucional, relacionadas con los procesos de trabajo y formación en salud en Brasil. EPS también se destacó como una herramienta para posibilitar cambios en la organización del trabajo, en los modelos de atención y conceptos de salud, permitiendo que el trabajador desarrolle autonomía y aumente las habilidades técnicas y relacionales.

Palabras clave: Formación profesional en salud; Educación para la salud; Sistema Único de Salud; Revisión.

\section{Introdução}

Os termos "educação em saúde" e "educação na saúde" são comumente utilizados como sinônimos para referir-se às práticas e processos educativos relativos ao trabalho na saúde. Entretanto, esses termos remetem a abordagens formativas que diferem entre si. Nesse sentido, torna-se fundamental a reflexão acerca desses conceitos, bem como a apreensão de suas diferenças, visto que esses entendimentos influenciam as ações e serviços em saúde.

A expressão "educação em saúde" designa processos educativos que têm o objetivo de instruir e potencializar cuidados com a saúde, incentivar a gestão social da saúde e o protagonismo do usuário em relação ao cuidado (Brasil, 2009). Nessa perspectiva, as ações de educação em saúde almejam a construção de conhecimentos e elaboração de entendimentos a partir do diálogo com os fazeres e saberes populares em saúde. Desse modo, busca-se promover a autonomia dos usuários e comunidades em relação às decisões em saúde e ao cuidado de si e de sua coletividade (Falkenberg et al., 2014).

Em contrapartida, o termo "educação na saúde" diz respeito à construção e organização de um conjunto de saberes, referentes às competências e habilidades para atuação profissional em saúde (Brasil, 2009). Dentre essas propostas educativas, daremos destaque a "educação na saúde", a qual apresenta a Educação Continuada (EC) e a Educação Permanente em Saúde (EPS) como duas modalidades distintas dessa proposta (Brasil, 2018).

A EC é caracterizada por toda atividade formativa realizada no âmbito das instituições de ensino e serviços de saúde, com uma carga horária estimada e a partir de metodologias tradicionais, que supõem uma transmissão passiva de informações e conhecimentos técnico-científicos. Nesse sentido, a EC pode ser compreendida ainda enquanto uma estratégia para a qualificação dos trabalhadores da saúde após a conclusão do ensino formal, superior ou técnico (Brasil, 2009; Falkenberg et al., 2014).

A partir do entendimento de que a formação se dá para além das instituições formais de ensino, tornou-se necessário investimentos e formulação de estratégias para qualificação dos trabalhadores da saúde, com vista à aproximação entre a população e os serviços de saúde, assim como entre os dispositivos e as instituições de ensino, dentre outras parcerias necessárias à promoção da integralidade do cuidado (Pinto et al., 2010).

À vista disso, a EPS refere-se a um conceito utilizado pelo Ministério da Saúde (MS), por meio da Política Nacional de Educação Permanente em Saúde (PNEPS), instituída em 2004 e atualizada em 2007, para fundamentar o trabalho em saúde e destacar seu caráter formativo (Figueiredo et al., 2017). Essa política, para além do provimento de condições para qualificação dos trabalhadores da saúde, tem por objetivo o fortalecimento do SUS e o alcance de seus princípios. Para isso, assume o compromisso de uma gestão descentralizada e participativa, por entender que orientações e diretrizes formuladas coletivamente por profissionais e usuários possam ser mais efetivas na resolução de conflitos, superação de desafios, necessidades e carências locais (Brasil, 2018).

A EPS, entendida também enquanto um instrumento político-pedagógico, designa qualquer ação, projeto e atividade educativa que envolva instituição de ensino em saúde, serviço de saúde, controle social e gestão em todas suas etapas; e que seja embasada por necessidades de trabalho e/ou de saúde dos usuários; de forma a objetivar uma análise institucional crítica, assim como a mudança de uma dada realidade no trabalho em saúde (Brasil, 2018).

De acordo com Pinto et al. (2010), ao trabalhar com EPS é fundamental compreendê-la quanto um processo, que se faz em meio às tensões e incômodos, responsáveis pelos deslocamentos que possibilitam a consolidação de conhecimentos resultante 
das diversidades de saberes que compõem o trabalho em saúde. O caminho para sua efetividade está nos esforços coletivos e diários para o planejamento e execução de suas ações, assim como na avaliação dos resultados e análise de seus reflexos nas práticas em saúde.

O diferencial dessa ferramenta viabilizadora expressa-se no fomento de espaços e na construção de conhecimentos coletivos, dispensando hierarquias em relação aos saberes e indivíduos que compõem o trabalho na saúde. A importância da coletividade é demonstrada na compreensão de que diferentes olhares e concepções servem para uma maior aproximação da realidade, que por sua vez contribuem para resolução das principais questões que atravessam a atuação profissional. Da mesma forma, permitem o desenvolvimento integral dos atores à medida que possibilita o aprender com o outro, no modelo de cogestão, por meio do próprio trabalho e práticas do cotidiano (Mendonça \& Nunes, 2011).

Apesar dos avanços alcançados, a PNEPS ainda apresenta impasses em relação a sua implementação e efetividade nos dispositivos de saúde. São constatadas dificuldades sobretudo em relação a apreensão de seu conceito pelos profissionais; falta de apoio e entrosamento da equipe; rotatividade de profissionais; escassez de procedimentos de avaliações das propostas de EPS; indefinição de critérios para elaboração de projetos e novas metodologias ativas, que incentivem o protagonismo e autonomia dos sujeitos (Pinto et al., 2010; Silva et al., 2016). Dito isso, vale problematizar: como a EPS tem se efetivado no cotidiano do SUS?

Figueiredo et al. (2017) revelam uma falta em relação à sistematização dos conhecimentos elaborados após a implementação da PNEPS. Desse modo, a relevância do presente estudo ainda se justifica pela premissa que pesquisas com a temática da EPS colaboram significativamente com os serviços de saúde, à medida que auxiliam na produção de conhecimentos úteis para o campo da saúde e destacam questões pertinentes ao trabalho e às práticas em saúde refletidas no cotidiano de trabalho (Leite, Pinto \& Fagundes, 2020). Diante dessa questão, objetivou-se conhecer como tem sido abordada a temática da Educação Permanente em Saúde nos artigos científicos da área.

\section{Metodologia}

Trata-se de uma Revisão Integrativa de Literatura, a qual consiste na sistematização concisa de conhecimentos científicos, obtidos de estudos empíricos e não-empíricos para compreensão e análise de determinada temática. A abordagem conta com etapas bem definidas e inclusão de elementos essenciais para o processo de coleta e análise dos dados. Refere-se ainda a uma metodologia bastante utilizada na área da saúde, em função do seu crescente número de informações e pesquisas (Souza, Silva \& Carvalho, 2010).

Essa revisão trabalhou com as seguintes questões orientadoras: quais os entendimentos sobre Educação Permanente em Saúde têm comparecido nos estudos da área? Como tem ocorrido o processo de Educação Permanente em Saúde no SUS? Quais as potencialidades e dificuldades decorrentes do trabalho com Educação Permanente em Saúde?

Foram realizadas buscas de artigos científicos nas bases de dados Scielo, PePSIC e Medline a partir do descritor: "Educação Permanente em Saúde". Foram utilizados como critérios de inclusão: artigos científicos disponíveis online na íntegra e em idioma português (realidade nacional), publicados no período de 2005 (ano seguinte a publicação da PNEPS) a 2020, que relacionavam no título, resumo e/ou nos objetivos a Educação Permanente em Saúde como temática central no estudo. Foram excluídos: teses, dissertações, trabalhos de conclusão de curso, capítulos de livro, artigos que não apresentam textos completos em português, trabalhos que discutiam a questão da Educação Permanente, mas não como temática principal da pesquisa, artigos que trabalhavam a EPS a partir da perspectiva de uma única área de formação profissional (a exemplo pesquisas que discutiam a EPS a partir da perspectiva apenas dos profissionais da enfermagem ou médicos), por entender o caráter multidisciplinar da Educação Permanente em Saúde; e demais estudos que não respondiam a nenhuma das questões levantadas por esse trabalho de 
revisão.

Como resultado da busca foram encontrados 60 artigos (47 no Scielo, 2 no Pepsic e 11 na Medline), aplicados os critérios de inclusão e exclusão obteve-se uma amostra de 22 artigos. Para análise do material foi utilizada a técnica de Análise de Conteúdo Temática (Minayo, 2004), que consiste na: leitura flutuante dos artigos selecionados conduzida pelas questões orientadoras, com fichamento do material em tabela composta por objetivos e principais resultados; seleção das unidades de análise também orientadas pelas questões de pesquisa; e consolidação das categorias temáticas.

Os dados provenientes da amostra final foram organizados em três categorias: Concepções sobre Educação Permanente em Saúde; Dificuldades decorrentes da Educação Permanente em Saúde; Potencialidades da Educação Permanente em Saúde.

\section{Resultados}

Os artigos selecionados foram organizados no Quadro 1 contendo autoria/ano de publicação, título, periódicos e objetivo.

Quadro 1 - Caracterização dos artigos selecionados sobre Educação Permanente em Saúde.

\begin{tabular}{|c|c|c|c|c|}
\hline Item & Autor (Ano) & Título & Periódico & Objetivo \\
\hline 1 & $\begin{array}{l}\text { Leite, Pinto \& } \\
\text { Fagundes (2020) }\end{array}$ & $\begin{array}{l}\text { Educação Permanente em Saúde: } \\
\text { reprodução ou contra-hegemonia? }\end{array}$ & $\begin{array}{l}\text { Revista Trabalho, } \\
\text { Educação e Saúde }\end{array}$ & $\begin{array}{c}\text { Refletir sobre as bases conceituais da educação } \\
\text { permanente em saúde }\end{array}$ \\
\hline 2 & $\begin{array}{l}\text { Figueiredo et al. } \\
\qquad(2017)\end{array}$ & $\begin{array}{c}\text { Dez anos de educação permanente } \\
\text { como política de formação em saúde } \\
\text { no Brasil }\end{array}$ & $\begin{array}{l}\text { Revista Trabalho, } \\
\text { Educação e Saúde }\end{array}$ & $\begin{array}{l}\text { Revelar a produção do conhecimento sobre } \\
\text { educação permanente em saúde com base no } \\
\text { levantamento bibliográfico }\end{array}$ \\
\hline 3 & $\begin{array}{l}\text { Silva et al. } \\
\quad(2016)\end{array}$ & $\begin{array}{l}\text { Avaliação da educação permanente no } \\
\text { processo de trabalho em saúde }\end{array}$ & $\begin{array}{l}\text { Revista Trabalho, } \\
\text { Educação e Saúde }\end{array}$ & $\begin{array}{c}\text { Conhecer as mudanças ocorridas no processo de } \\
\text { trabalho decorrentes da educação permanente } \\
\text { em saúde }\end{array}$ \\
\hline 4 & $\begin{array}{c}\text { Gigante \& } \\
\text { Campos (2016) }\end{array}$ & $\begin{array}{l}\text { Política de formação e educação } \\
\text { permanente em saúde no Brasil: bases } \\
\text { legais e referências teóricas }\end{array}$ & $\begin{array}{l}\text { Revista Trabalho, } \\
\text { Educação e Saúde }\end{array}$ & $\begin{array}{c}\text { Discutir as inter-relações dos relatórios das } \\
\text { Conferências Nacionais de Saúde com as } \\
\text { propostas apresentadas em documentos oficiais } \\
\text { do Sistema Único de Saúde }\end{array}$ \\
\hline 5 & $\begin{array}{l}\text { Diniz \& Sá } \\
\text { (2019) }\end{array}$ & $\begin{array}{l}\text { O uso das narrativas e do dispositivo } \\
\text { grupal na formação/educação } \\
\text { permanente dos profissionais de } \\
\text { saúde: uma revisão de literatura }\end{array}$ & $\begin{array}{l}\text { Interface - } \\
\text { Comunicação Saúde } \\
\text { Educação }\end{array}$ & $\begin{array}{l}\text { Mapear as estratégias de formação/educação } \\
\text { permanente dos profissionais de saúde que } \\
\text { utilizam o dispositivo grupal e as narrativas }\end{array}$ \\
\hline 6 & $\begin{array}{l}\text { Silva \& Scherer } \\
\quad(2020)\end{array}$ & $\begin{array}{l}\text { A implementação da Política Nacional } \\
\text { de Educação Permanente em Saúde na } \\
\text { visão de atores que a constroem }\end{array}$ & $\begin{array}{l}\text { Interface - } \\
\text { Comunicação Saúde } \\
\text { Educação }\end{array}$ & $\begin{array}{l}\text { Compreender os fatores que favoreceram ou } \\
\text { dificultaram a implementação da EPS }\end{array}$ \\
\hline 7 & $\begin{array}{l}\text { França et al. } \\
\quad(2017)\end{array}$ & $\begin{array}{c}\text { Política de Educação Permanente em } \\
\text { Saúde no Brasil: a contribuição das } \\
\text { Comissões Permanentes de Integração } \\
\text { Ensino-Serviço }\end{array}$ & $\begin{array}{l}\text { Ciência \& Saúde } \\
\text { Coletiva }\end{array}$ & $\begin{array}{l}\text { Analisar o papel das CIES na implementação da } \\
\text { Política de Educação Permanente em Saúde }\end{array}$ \\
\hline 8 & $\begin{array}{l}\text { Cardoso et al. } \\
\text { (2017) }\end{array}$ & $\begin{array}{c}\text { A Política Nacional de Educação } \\
\text { Permanente em Saúde nas Escolas de } \\
\text { Saúde Pública: reflexões a partir da } \\
\text { prática }\end{array}$ & $\begin{array}{l}\text { Ciência \& Saúde } \\
\text { Coletiva }\end{array}$ & $\begin{array}{c}\text { Analisar aspectos da implementação da Política } \\
\text { Nacional de Educação Permanente em Saúde } \\
\text { nas Escolas de Saúde Pública }\end{array}$ \\
\hline 9 & Cecicm (2005) & $\begin{array}{l}\text { Educação Permanente em Saúde: } \\
\text { descentralização e disseminação de } \\
\text { capacidade pedagógica na saúde }\end{array}$ & $\begin{array}{l}\text { Ciência \& Saúde } \\
\text { Coletiva }\end{array}$ & $\begin{array}{c}\text { Apresentar o modo como foi produzida a } \\
\text { política de EPS e registrar os principais } \\
\text { aspectos relativos aos } 16 \text { meses de } \\
\text { implementação }\end{array}$ \\
\hline
\end{tabular}




\begin{tabular}{|c|c|c|c|c|}
\hline 10 & $\begin{array}{l}\text { Souza, Anton \& } \\
\text { Oliveira (2019) }\end{array}$ & $\begin{array}{c}\text { Educação permanente em saúde e } \\
\text { desenvolvimento adulto: a experiência } \\
\text { das oficinas fotográficas de } \\
\text { sensibilização do olhar }\end{array}$ & $\begin{array}{l}\text { Gerais: Revista } \\
\text { Interinstitucional de } \\
\text { Psicologia }\end{array}$ & $\begin{array}{l}\text { Apresentar e analisar uma iniciativa de } \\
\text { formação no trabalho desenvolvida como parte } \\
\text { da produção de um livro sobre experiências de } \\
\text { EPS }\end{array}$ \\
\hline 11 & $\begin{array}{c}\text { Peres, Silva \& } \\
\text { Barba (2016) }\end{array}$ & $\begin{array}{c}\text { Desafios e potencialidades do } \\
\text { processo de educação permanente em } \\
\text { saúde }\end{array}$ & $\begin{array}{l}\text { Revista Trabalho, } \\
\text { Educação e Saúde }\end{array}$ & $\begin{array}{c}\text { Apresentar uma análise sobre o processo de } \\
\text { implementação da educação permanente em } \\
\text { saúde no município de São Carlos, no estado de } \\
\text { São Paulo }\end{array}$ \\
\hline 12 & $\begin{array}{l}\text { Yamamoto, } \\
\text { Machado \& Silva } \\
\text { Júnior (2015) }\end{array}$ & $\begin{array}{c}\text { Educação permanente em saúde como } \\
\text { prática avaliativa amistosa à } \\
\text { integralidade em Teresópolis, Rio de } \\
\text { Janeiro. }\end{array}$ & $\begin{array}{l}\text { Revista Trabalho, } \\
\text { Educação e Saúde }\end{array}$ & $\begin{array}{l}\text { Discutir o papel da educação permanente em } \\
\text { saúde como prática avaliativa amistosa à } \\
\text { integralidade no cotidiano dos serviços de saúde }\end{array}$ \\
\hline 13 & $\begin{array}{l}\text { Lima, } \\
\text { Albuquerque \& } \\
\text { Wenceslau } \\
\text { (2014) }\end{array}$ & $\begin{array}{c}\text { Educação permanente em saúde } \\
\text { segundo os profissionais da gestão de } \\
\text { Recife, Pernambuco }\end{array}$ & $\begin{array}{l}\text { Revista Trabalho, } \\
\text { Educação e Saúde }\end{array}$ & $\begin{array}{l}\text { Discutir o que pensam os profissionais da } \\
\text { gestão sobre os processos de educação } \\
\text { permanente em saúde no município de Recife }\end{array}$ \\
\hline 14 & $\begin{array}{l}\text { Silva, Leite \& } \\
\text { Pinno (2014) }\end{array}$ & $\begin{array}{c}\text { Contribuições das comissões de } \\
\text { integração ensino-serviço na educação } \\
\text { permanente em saúde }\end{array}$ & $\begin{array}{l}\text { Revista Trabalho, } \\
\text { Educação e Saúde }\end{array}$ & $\begin{array}{l}\text { Conhecer os fatores que potencializam ou } \\
\text { fragilizam a construção e o desenvolvimento } \\
\text { dos planos regionais de educação permanente } \\
\text { na concepção dos membros participantes }\end{array}$ \\
\hline 15 & $\begin{array}{l}\text { Nicoletto et al. } \\
\text { (2013) }\end{array}$ & $\begin{array}{c}\text { Desafios na implantação, } \\
\text { desenvolvimento e sustentabilidade da } \\
\text { Política de Educação Permanente em } \\
\text { Saúde no Paraná, Brasil }\end{array}$ & Saúde e Sociedade & $\begin{array}{l}\text { Compreender o processo de implantação, } \\
\text { desenvolvimento e sustentabilidade da Política } \\
\text { Nacional de Educação Permanente em Saúde } \\
\text { (EPS) no Paraná. }\end{array}$ \\
\hline 16 & $\begin{array}{l}\text { Mendonça \& } \\
\text { Nunes (2011) }\end{array}$ & $\begin{array}{l}\text { Necessidades e dificuldades de tutores } \\
\text { e facilitadores para implementar a } \\
\text { política de educação permanente em } \\
\text { saúde em um município de grande } \\
\text { porte no estado do Paraná, Brasil. }\end{array}$ & $\begin{array}{l}\text { Interface - } \\
\text { Comunicação Saúde } \\
\text { Educação }\end{array}$ & $\begin{array}{l}\text { Descobrir quais necessidades e dificuldades } \\
\text { durante o processo de implementação da EPS }\end{array}$ \\
\hline 17 & $\begin{array}{l}\text { Nogueira et al. } \\
\qquad(2019)\end{array}$ & $\begin{array}{l}\text { Atenção ao idoso: práticas de } \\
\text { educação permanente do Núcleo de } \\
\text { Apoio à Saúde da Família }\end{array}$ & $\begin{array}{l}\text { Revista Escola de } \\
\text { Enfermagem USP }\end{array}$ & $\begin{array}{c}\text { Desvelar as práticas de EPS desenvolvidas pelo } \\
\text { NASF na atenção ao idoso }\end{array}$ \\
\hline 18 & $\begin{array}{l}\text { Bispo \& Moreira } \\
\quad(2017)\end{array}$ & $\begin{array}{c}\text { Educação permanente e apoio } \\
\text { matricial: formação, vivências e } \\
\text { práticas dos profissionais dos Núcleos } \\
\text { de Apoio à Saúde da Família e das } \\
\text { equipes apoiadas }\end{array}$ & $\begin{array}{l}\text { Cadernos de Saúde } \\
\text { Pública }\end{array}$ & $\begin{array}{l}\text { Compreender e analisar como os processos de } \\
\text { educação permanente são vivenciados pelos } \\
\text { profissionais dos NASF e das EqSF }\end{array}$ \\
\hline 19 & Sena et al. (2017) & $\begin{array}{c}\text { Educação permanente nos serviços de } \\
\text { saúde: atividades educativas } \\
\text { desenvolvidas no estado de Minas } \\
\text { Gerais, Brasil }\end{array}$ & $\begin{array}{l}\text { Revista Gaúcha de } \\
\text { Enfermagem }\end{array}$ & $\begin{array}{c}\text { Analisar atividades educativas desenvolvidas no } \\
\text { estado de Minas Gerais, Brasil, consideradas } \\
\text { como EPS }\end{array}$ \\
\hline 20 & $\begin{array}{l}\text { Silva et al. } \\
\text { (2017) }\end{array}$ & $\begin{array}{c}\text { Educação permanente em saúde na } \\
\text { atenção básica: percepção dos gestores } \\
\text { municipais de saúde }\end{array}$ & $\begin{array}{l}\text { Revista Gaúcha de } \\
\text { Enfermagem }\end{array}$ & $\begin{array}{c}\text { Conhecer as estratégias de educação em saúde } \\
\text { preconizadas e desenvolvidas aos trabalhadores } \\
\text { da atenção básica pelos gestores. }\end{array}$ \\
\hline 21 & $\begin{array}{l}\text { Mishima et al. } \\
\text { (2015) }\end{array}$ & $\begin{array}{l}\text { A perspectiva dos gestores de uma } \\
\text { região do Estado de São Paulo acerca } \\
\text { da Educação Permanente em Saúde }\end{array}$ & $\begin{array}{l}\text { Revista Escola de } \\
\text { Enfermagem USP }\end{array}$ & $\begin{array}{c}\text { Analisar os conceitos de EPS, operados pelos } \\
\text { gestores municipais e traduzidos nos } \\
\text { documentos oficiais. }\end{array}$ \\
\hline 22 & $\begin{array}{l}\text { Miccas \& Batista } \\
\quad(2014)\end{array}$ & $\begin{array}{l}\text { Educação permanente em saúde: } \\
\text { metassíntese }\end{array}$ & $\begin{array}{l}\text { Revista Saúde } \\
\text { Pública }\end{array}$ & $\begin{array}{l}\text { Realizar metassíntese da literatura sobre os } \\
\text { principais conceitos e práticas relacionados à } \\
\text { educação permanente em saúde. }\end{array}$ \\
\hline
\end{tabular}

Fonte: Autores.

Dos artigos selecionados um é de 2005, um de 2011, um de 2013, três de 2014, dois de 2015, três de 2016, seis de 2017, três de 2019 e dois de 2020; publicados em seis revistas da área de saúde coletiva (17), duas da enfermagem (4) e uma da psicologia (1). Todos os artigos com objetivo que atende o critério de inclusão para esse estudo, conforme presente no quadro. 


\subsection{Concepções de Educação Permanente em Saúde}

Esta categoria apresenta os entendimentos de EPS abordados pelos estudos dessa pesquisa. Dos artigos analisados, 19 apresentam uma conceituação do termo, incluindo, os objetivos da EPS no contexto do SUS, com base, em sua maioria, em documentos ministeriais, como a própria PNEPS. Nas palavras de Silva, Leite e Pinno (2014, p. 409), a EPS tem por objetivo: produzir novos pactos e acordos coletivos para o SUS; ter como foco o processo de trabalho: atenção, gestão, educação e formação; atuar de forma integrativa com enfoque multiprofissional e interdisciplinar; trabalhar na geração de coletivos organizados para a produção e a gestão de recursos humanos; e possibilitar a construção de estratégias de maior potencialidade.

Observa-se no texto de Mishima et al. (2015) uma definição de EPS proveniente de concepções veiculadas pela Organização Pan-Americana da Saúde (OPAS), que a assume enquanto ferramenta capaz de reconstruir o conceito de trabalho e produzir novas orientações para educação no trabalho, pelo trabalho e para o trabalho em diferentes dispositivos e serviços. Nesta perspectiva, a EPS teria objetivo de contribuir com melhores condições de saúde para população, de forma a torná-la agente ativo no processo de atenção à saúde. Insere-se ainda nesse contexto a problematização do processo de trabalho para transformação das práticas, relações e estruturas de poder que permeiam o trabalho no campo da saúde (Mishima et al., 2015). Destaca-se dentre as conceituações, a associação da EPS à aprendizagem significativa (Miccas \& Batista, 2014; Lima, Alburqueque \& Wenceslau, 2014; Yamamoto, Machado \& Silva Júnior, 2015; Gigante \& Campos, 2016; Figueiredo, et al., 2017; Cardoso et al., 2017; Diniz \& Sá, 2019; Souza, Anton \& Oliveira, 2019; Leite, Pinto \& Fagundes, 2020; Silva \& Scherer, 2020), explicada pelos artigos, como aquele conhecimento que se constrói coletivamente a partir dos saberes de todos os envolvidos, de modo que faça sentido no cotidiano das práticas dos educandos. A EPS é anunciada como uma proposta política e pedagógica, que se baseia na aprendizagem significativa e na perspectiva de transformação das práticas profissionais (Ceccim, 2005; Yamamoto, Machado \& Silva Júnior, 2015; Gigante \& Campos,2016; Figueiredo, et al., 2017; Cardoso et al., 2017; Diniz \& Sá, 2019; Souza, Anton \& Oliveira, 2019; Leite, Pinto \& Fagundes, 2020; Silva \& Scherer, 2020). Nas palavras de Ceccim (2005), a EPS consiste em uma "estratégia fundamental às transformações do trabalho no setor para que venha a ser lugar de atuação crítica, reflexiva, propositiva, compromissada e tecnicamente competente" (p.976)

Gigante e Campos (2016) acrescentam, que para além de uma proposta política, a EPS consiste em uma "prática de ensino-aprendizagem" que se apoia em "elementos das metodologias educacionais ativas (...) no conceito de ensino problematizador, com produção de conhecimento mediante análise crítica do cotidiano, horizontalidade entre educador e educando e prática dialógica". A EPS comparece como uma "proposta de prática pedagógica que coloca o cotidiano do trabalho em saúde como central aos processos educativos, ao mesmo tempo que o coloca sob problematização, isto é, em autoanálise e autogestão" (Yamamoto, Machado \& Silva Júnior, 2015, p. 618). Leite, Pinto e Fagundes (2020) também destacam a perspectiva de análise integral do contexto e das práticas, que deve estar presente no processo de EPS. Neste sentido, Nogueira, Acioli, Carreira e Baldissera (2019) conceituam a EPS como "intervenção educativa deliberada cujo eixo é a discussão crítica das práticas concretas, as quais envolvem todos os profissionais implicados e se alicerça na abordagem dialógica por essência" (p. 6). Para Cardoso et al. (2017), a EPS se refere a uma pedagogia problematizadora, baseada na relação dialógico-dialética entre educador e educando, de modo que ambos aprendem juntos. Trata-se para Bispo e Moreira (2017) de um processo dialógico. Lima, Alburqueque e Wenceslau (2014), Diniz e Sá (2019) e Nogueira et al. (2019) afirmam a EPS como um momento de troca de experiência, de fazer junto e de integração entre profissionais de saúde; nesta direção, os autores enumeram alguns dispositivos como meios de pôr em prática a EPS, como: o atendimento compartilhado, o grupo educativo ou terapêutico, a discussão de caso, a visita domiciliar, o apoio matricial, o apoio institucional, o uso do projeto terapêutico singular (PTS) e a reunião entre profissionais. Nesta mesma direção, a EPS é anunciada como "uma prática de produção e compartilhamento de conhecimento vinculado ao cotidiano do trabalho" (Souza, Anton \& Oliveira, 2019, p. 339). 
Comparece ainda, o entendimento da EPS como estratégia voltada à mudança da organização do processo de trabalho e da qualidade da gestão e da assistência (Silva, Leite \& Pinno, 2014; Mishima et al., 2015; Gigante \& Campos, 2016; Silva et al., 2016; Sena et al., 2017; Silva, Soder, Petry \& Oliveira, 2017; Leite, Pinto \& Fagundes, 2020). Nicoletto et al. (2013) também define a EPS como uma "estratégia para articular os diversos atores e promover transformações nas práticas sanitárias" (p. 1101). De modo parecido, a EPS é concebida enquanto um instrumento de organização das equipes na conformação de coletivos baseados em práticas multiprofissionais (Mishima et al., 2015). Leite, Pinto e Fagundes (2020) trazem o conceito de Furter (1974, p. 79) sobre EPS, que a define como: "um processo ininterrupto de aprofundamento tanto da experiência pessoal como da vida coletiva que se traduz pela dimensão educativa que cada ato, cada gesto, cada função assumirá, qualquer que seja a situação em que encontramos, qualquer que seja a etapa de existência que estejamos vivendo".

Miccas e Batista (2014) entendem a EPS como uma educação que se dá ao longo da vida, por meio de ressignificação do desenvolvimento pessoal e interpessoal contínuo, concebendo que o aprendizado no trabalho vai além da dimensão técnica. Os autores também trazem a ideia da EPS como uma "construção compartilhada de conceitos que supera a cultura organizacional baseada na centralidade de decisões” (Miccas \& Batista, 2014, p. 173).

Diniz e Sá (2019) destacam dois entendimentos sobre a EPS, um refere a EPS como um processo de formação durante toda a vida profissional, que se filia às matrizes das teorias interacionistas, construtivistas e da ação dialógica e problematizadora freireana; e outro entendimento que concebe a EPS como intervenção institucional envolvendo profissionais, gestores, usuários em seus processos de cuidado em saúde.

Comparece também, o entendimento da EPS como política de formação, desenvolvimento e qualificação dos trabalhadores para o SUS e consequente aperfeiçoamento do processo de trabalho (Silva \& Scherer, 2020; Mishima et al., 2015; Silva, Soder, Petry \& Oliveira, 2017). Silva, Soder, Petry e Oliveira (2017) resumem alguns sentidos relacionados a EPS:

valorização do trabalho no desenvolvimento pessoal; a articulação do fazer educativo com o processo de trabalho; a articulação da educação com a atenção; a integração das ações educativas sob diferentes dimensões, junto à equipe multiprofissional e interdisciplinar; o uso de estratégias educativas em prol de transformações das práticas de saúde, além de um olhar diferenciado sobre a integralidade da atenção aos usuários e à população (p. 6).

Nestas conceituações trazidas pelos artigos analisados, comparecem ainda, a associação feita, no cotidiano das práticas, do conceito de EPS ao de Educação Continuada (EC). Aparentemente, tal associação se relaciona ao fato da OPAS ter disseminado a ideia da Educação Permanente como uma 'nova' concepção de EC (Leite, Pinto \& Fagundes, 2020). Gigante e Campos (2016, p. 749) resgatam que "o termo 'educação continuada' apareceu pela primeira vez na VI Conferência Nacional de Saúde, em 1977, relacionado à necessidade de se manter a inclusão de novos conhecimentos na carreira de sanitarista".

Assim, a EPS aparece, no cotidiano das práticas, como sinônimo daqueles cursos pontuais de capacitação demandados por gestores e/ou cursos formadores ofertados por instituições de ensino (Nicoletto et al., 2013; Silva, Leite \& Pinno, 2014; Lima, Alburqueque \& Wenceslau, 2014; Miccas \& Batista, 2014; Mishima et al., 2015; Silva, Soder, Petry \& Oliveira, 2017). Silva et al. (2016) trazem a negativa de que a EPS não se limita a capacitações técnicas e a atualização de conhecimentos. Por fim, Gigante e Campos (2016), na diferenciação entre EPS e EC, explicam que essa última se inscreve como uma prática educativa tradicional - modelo pedagógico centrado na transmissão de conhecimento - voltada à recuperação de conhecimentos e habilidades esquecidas e ao acompanhamento das mudanças científicas e tecnológicas que possam melhorar o desempenho profissional.

\subsection{Dificuldades relativas à Educação Permanente em Saúde}

Essa categoria apresenta conteúdos referentes às dificuldades relacionadas à EPS mencionadas nos artigos analisados, sendo que 16 artigos analisados apresentam essas dificuldades. Destaca-se a questão do financiamento da proposta de EPS como 
uma das dificuldades para sua consolidação (Miccas \& Batista, 2014; Silva et al., 2016; França et al., 2017; Silva \& Scherer, 2020). Nesta discussão, Silva e Scherer (2020) destacam a interrupção do repasse de recursos pelo Governo Federal, desde 2011, para a implementação da EPS, como um desafio importante.

Para Leite, Pinto e Fagundes (2020, p. 2), a "pedagogia hegemônica de matriz flexneriana das instituições de ensino superior" obstaculizam a efetivação da EPS no que ela se propõe como um processo de ensino-aprendizagem participativo e focado na realidade dos serviços. Silva et al. (2016) corroboram tal discussão quando apontam como dificultador as "ações educativas focalizadas no tecnicismo reducionista" (p. 766). Ou ainda, quando se enfatiza como dificuldade o predomínio de uma assistência à saúde fragmentada, processos de trabalho compartimentados entre concepção e execução, práticas curativistas e centradas em procedimentos, com pouca abertura para o diálogo, escuta, integralidade e construção coletiva (Mendonça \& Nunes, 2011; Lima, Alburqueque \& Wenceslau, 2014; Peres, Silva \& Barba, 2016; Silva et al., 2016; Silva, Soder, Petry \& Oliveira, 2017).

Acrescido disso, os artigos também apontam como dificuldade as noções vagas e desalinhadas sobre a EPS, associadas com frequência a cursos ofertados de acordo com o modelo escolar (Nicoletto et al., 2013; Silva, Leite \& Pinno, 2014; Mishima et al., 2015; Peres, Silva \& Barba, 2016; Silva et al., 2016; Bispo Júnior \& Moreira, 2017; Silva, Soder, Petry \& Oliveira, 2017; Silva \& Scherer, 2020). Predomina, na pauta de discussão da EPS, cursos pontuais de capacitação, ofertados principalmente em decorrência das demandas de gestores e cursos formadores organizados por instituições de ensino, que se distanciam dos preceitos da EPS (Silva, Leite \& Pinno, 2014).

Para Ceccim (2005) o desafio está em "ultrapassar a utilização pedagógica de natureza educacional da formulação trabalhada pela Organização Pan-Americana da Saúde, relativa à Educação Permanente do Pessoal da Saúde, para implica-la com o caráter situacional das aprendizagens nos próprios cenários de trabalho da saúde, em todas as suas dimensões, conectandoa às ações contra-hegemônicas necessárias” (p. 979)

Relacionada a essa discussão, comparece como desafio: os trabalhadores se apropriarem de uma lógica formativa em que as decisões sobre seus processos de trabalho não sejam impostas (Nicoletto et al., 2013; Silva, Leite \& Pinno, 2014; Peres, Silva \& Barba, 2016; Silva, Soder, Petry \& Oliveira, 2017). Nas palavras de Silva, Leite e Pinno (2014), o desafio da EPS é conseguir "estimular o desenvolvimento da consciência dos sujeitos em relação ao seu contexto, bem como seu envolvimento, participação e responsabilidade em seu processo educativo" (p. 409). Mendonça e Nunes (2011) e Mishima et al. (2015) também falam de uma dificuldade dos trabalhadores da saúde em reconhecer os problemas do dia a dia enquanto fundamento para o exercício da EPS, bem como a falta de comprometimento e responsabilização dos profissionais com o serviço público, como obstáculos à consolidação da EPS. O desafio da EPS está em "estimular o desenvolvimento dos profissionais no seu contexto e sua responsabilidade no processo contínuo de educação" (Silva, Soder, Petry \& Oliveira, 2017, p. 5).

Apresenta-se como desafio à EPS também, o reconhecimento das práticas que se dão no encontro com o outro e da construção de estratégias de colaboração que ampliem o impacto desses encontros (Souza, Anton \& Oliveira, 2019). Ceccim (2005) e Souza, Anton e Oliveira (2019) corroboram com Merhy, que os maiores desafios da EPS são: "produzir auto interrogação de si mesmo no agir produtor do cuidado; colocar-se ético-politicamente em discussão, no plano individual e coletivo, do trabalho" (p. 173)

Por outro lado, comparece como dificuldade a limitação de governabilidade dos profissionais, que diz de prejuízo à autonomia dos trabalhadores no exercício da proposta em questão (Mendonça \& Nunes, 2011). Tal configuração se relaciona à não institucionalidade da EPS como política; em outras palavras, a pouca priorização da EPS pela gestão (Mendonça \& Nunes, 2011; Lima, Albuquerque \& Wenceslau, 2014; Silva et al., 2016; França et al., 2017; Bispo Júnior \& Moreira, 2017; Silva, Soder, Petry \& Oliveira, 2017). Nas palavras de Mendonça e Nunes (2011) “para a EPS ser assumida como uma estratégia de mudança, 
é preciso que ela seja institucionalizada, pois é preciso garantir um espaço institucional para assegurar a sustentabilidade dessa política" (p. 879).

Silva e Scherer (2020) apontam como dificuldade à efetivação da EPS, o fato dos atos de EPS serem pouco documentados e reconhecidos como parte substancial de uma estratégia de mudança institucional, o que, segundo as autoras, resulta na identificação e compreensão mais facilmente de ofertas educativas verticalizadas e normatizadas.

Silva, Soder, Petry e Oliveira (2017) enumeram como dificuldades a efetivação da EPS, para além da falta de apoio institucional: o desconhecimento das atividades educativas, a falta de interação setorial, a falta de comunicação e o comprometimento com as mudanças", "o cansaço físico, a indisponibilidade de horários, o duplo emprego, a resistência a mudanças, a falta de tempo, os excessos de demandas de tarefas, o pouco comprometimento por parte dos profissionais, a remuneração inadequada, a falta de incentivos (p. 6).

Outros artigos apontam como dificuldades: a sobrecarga dos profissionais (Mendonça \& Nunes, 2011; Silva, Leite \& Pinno, 2014) e a existência de política partidária e não de saúde (Peres, Silva \& Barba, 2016; Silva, Leite \& Pinno, 2014); "a ausência de planejamento, diminuto contingente de trabalhadores, com sobrecarga de trabalho" (Silva et al., 2016, p. 766); "a rotatividade dos gestores em todas as esferas, a inexistência de apoio e de referência técnica, a baixa governança e a fragmentação das ações de EPS" (Silva \& Scherer, 2020); a descontinuidade e mudanças de enfoque da proposta de EPS (França et al., 2017). Observa-se também em outro estudo a insipiência de planejamento e ações de coordenação da EPS nos municípios (Peres, Silva \& Barba, 2016).

Em relação a incompatibilidade encontrada entre as políticas de saúde e políticas de governo, as autoras Peres, Silva e Barba (2016) apontam ainda, que a EPS assume um carácter de gestão regionalizada, ao qual permite trabalhar a PNEPS de acordo com as especificidades e particularidades de cada território, sendo que isso jamais deve-se traduzir em possibilidades de adequação às políticas de governo, baseadas nos interesses partidários e políticos.

Alguns artigos anunciam ainda como um desafio a efetivação da EPS, o fato dos processos de monitoramento e avaliação relativos a essa estratégia educacional, ser incipiente, assistemático, desfocado ou inexistente (Silva et al., 2016; Silva \& Scherer, 2020). Miccas e Batista, 2014, Lima, Albuquerque e Wenceslau (2014) e Silva e Scherer (2020) destacam também, como dificuldade a consolidação da EPS: a pouca interlocução entre os instrumentos da política de gestão do trabalho, o planejamento e a área da educação na saúde. Miccas e Batista (2014) acrescentam a esse debate a falta de articulação entre ensino-serviço-comunidade, que representa um obstáculo ao planejamento e definição das necessidades de ações requeridas pela EPS.

Neste contexto, de modo pouco explicativo, Leite, Pinto e Fagundes (2020) anunciam como dificuldade a efetivação da EPS “as mudanças no mundo do trabalho em geral" e "obstáculos estruturais" que limitam as transformações dos espaços de trabalho.

Comparece ainda como uma dificuldade, o entendimento de que EPS é uma questão a ser trabalhada com as equipes da rede básica, não reconhecendo "que o essencial é refletir sobre a micropolítica que se desenvolve em todos os lugares onde se produz o cuidado" (Sena et al., 2017, p. 6).

Por fim, nas palavras Miccas e Batista (2014, p. 180) tem-se como desafio a implementação da EPS: "baixa disponibilidade de profissionais ou sua alta rotatividade nos setores, (...) crescente especialização e dependência de tecnologias mais sofisticadas, predomínio da formação hospitalar, conceitos imprecisos de integralidade e promoção da saúde e cisão nas equipes em relação a treinamentos, capacitações e reuniões". 


\subsection{Potencialidades da Educação Permanente em Saúde}

Essa categoria apresenta as potencialidades decorrentes do trabalho com EPS descritas nos artigos analisados. Dos 22 artigos, 14 abordam as potencialidades da EPS para o SUS. Destaca-se a potencialidade da EPS em contribuir para a transformação dos trabalhos e das práticas em saúde, na direção de reorganização e melhoria da gestão e da qualidade dos serviços, sustentados no princípio da equidade da atenção em saúde (Mishima et al., 2015; Yamamoto, Machado \& Silva Júnior, 2015; França et al., 2017; Silva, Soder, Petry \& Oliveira, 2017; Leite, Pinto \& Fagundes, 2020). Nas palavras de Silva, Soder, Petry e Oliveira (2017) a potencialidade da EPS está em "aperfeiçoar práticas, gerar mudanças organizacionais, relacionais, interpessoais e aprimorar o processo de trabalho" (p. 6).

Para Diniz e Sá (2019) a potencialidade da EPS está em favorecer "a elaboração, pelos profissionais de saúde, dos sentidos de sua prática e de sua implicação como sujeitos com a realidade dos serviços onde se inserem, na relação com os usuários e com os profissionais da equipe" (p. 3). Semelhantemente, Peres, Silva e Barba (2016) evidenciam como positivo o fato da EPS colaborar para uma gestão participativa tanto dos trabalhadores, quanto da comunidade. Mishima et al. (2015) adicionam a isso a partilha das responsabilidades e as trocas realizadas entre profissionais, usuários e instituições de ensino. Acrescido disso, Leite, Pinto e Fagundes (2020) discutem a potencialidade da EPS articular vontades coletivas, para a construção de um cenário político institucional contra-hegemônico, baseado em atitudes críticas, conscientes e inventivas por parte dos sujeitos envolvidos. Assim, nas palavras dos autores: "a educação permanente em saúde parece possibilitar a criação das condições para que os sujeitos possam ser intelectuais e políticos, para agir e pensar, conceber e propor, analisar e 'prever', exaltando a dialética da unidade, do diverso, da totalidade" (Leite, Pinto \& Fagundes, 2020, p. 10).

Contudo, destaca-se também, a possibilidade da EPS “desencadear processos hegemônicos, na medida em que, dentro de sua proposta de formação dos trabalhadores, pode simultaneamente, produzir sujeitos aderentes ao status quo" (Leite, Pinto \& Fagundes, 2020, p. 11).

Ainda assim, prevalece entre os artigos analisados a perspectiva de que a EPS tem a potencialidade de produção de sujeitos reflexivos, críticos, ativos, autônomos e construtores de saber (Miccas \& Batista, 2014; Yamamoto, Machado \& Silva Júnior, 2015; Gigante \& Campos, 2016; França et al., 2017; Leite, Pinto \& Fagundes, 2020). Nas palavras de Yamamoto, Machado e Silva Júnior (2015, p. 622), a potencialidade da EPS está na "melhora do profissional de saúde por meio do incremento de suas habilidades técnicas e relacionais e da otimização de seu processo de trabalho".

Comparece a potencialidade da EPS modificar e viabilizar estratégias educativas (Gigante \& Campos, 2016; França et al., 2017; Silva, Soder, Petry \& Oliveira, 2017), na direção de práticas participativas e compartilhadas, bem como, de fomento à integração ensino-serviço (Lima, Alburqueque \& Wenceslau, 2014; Gigante \& Campos, 2016). Afirma-se que a EPS possibilita o acesso e a obtenção de novos conhecimentos, indissoluvelmente ligados às mudanças na ação e no contexto das práticas (Silva, Soder, Petry \& Oliveira, 2017; Nogueira, Acioli, Carreira \& Baldissera, 2019). Assim, a EPS favorece ainda, a construção coletiva e facilita o enfrentamento dos problemas evidenciados no cotidiano (Mendonça \& Nunes, 2011; Silva, Soder, Petry \& Oliveira, 2017).

Ceccim (2005) e Yamamoto, Machado e Silva Júnior (2015) descrevem que a EPS tem a potencialidade de contribuir para a efetivação da integralidade e dos demais princípios do SUS, na medida em que congregar gestão, formação, práticas de saúde e controle social na adequação da oferta de serviços e atua na ressignificação dos "perfis" de atuação dos profissionais de saúde, gestores e usuários, rumo ao fortalecimento da atenção à saúde no SUS. Comparece também, a potencialidade da EPS contribuir com as práticas de resistência para afirmação de espaços democráticos, já que tem em sua proposta agregar todos esses atores sociais (Souza, Anton \& Oliveira, 2019). 
Diniz e Sá (2019) referem como potencialidade da EPS promover a mudança na orientação da concepção de saúde e do modelo de assistência, transformando as práticas de saúde, de acordo com os princípios e diretrizes do SUS. As autoras trazem ainda, a potencialidade da EPS promover democratização e autonomia, contribuir para a humanização e melhoria do cuidado, transformar as práticas de saúde, fortalecer o trabalho em equipe multiprofissional, de forma integrada, para a construção de um projeto comum.

Por fim, comparece como potencialidade da EPS: contribuir para a valorização e a satisfação do trabalhador, a interação entre profissionais de diferentes instituições para a troca de experiências teóricas e práticas e a qualificação da atenção aos usuários (Silva, Soder, Petry \& Oliveira, 2017).

\section{Discussão}

A partir da análise dos dados desta revisão, observou-se que alguns aspectos decorrentes do trabalho com a EPS foram abordados em mais de uma categoria deste estudo. Por exemplo, na categoria acerca das concepções, a EPS é caracterizada pelas mudanças provocadas nas práticas de trabalho ou por viabilizar uma aproximação com a comunidade. De modo parecido, esses aspectos são destacados nas demais categorias, comparecendo ora como uma potencialidade, ora como um impasse à efetivação da proposta. Pode-se observar o mesmo em relação a outros pontos destacados pelas experiências e reflexões relativas à temática, por exemplo: a aproximação com instituições de ensino; uma gestão participativa; envolvimento entre as equipes e profissionais. O que, por sua vez, pode funcionar como um marcador das diferentes características e especificidades que o trabalho com EPS pode assumir nos diferentes territórios e comunidades.

As concepções trazidas pelos artigos analisados permitem afirmar que os entendimentos em relação a EPS remetem a vários elementos do campo da educação, trabalho e saúde. Morosini, Fonseca e Pereira (2008) caracterizam este campo de interseção como espaço de disputa entre os projetos de sociedade, as concepções de educação, saúde e trabalho implicadas na construção, organização e atualização das práticas e conhecimentos em saúde. Nesse sentido, torna-se fundamental a reflexão acerca dos referenciais que constituem estas noções.

A EPS fundamenta-se principalmente na pedagogia problematizadora de Paulo Freire, a partir do uso de metodologias ativas para uma aprendizagem significativa. Nesse modelo, prioriza-se o debate e a construção coletiva de conhecimentos, em detrimento da reprodução e transmissão passiva de informações. Acredita-se que a problematização possa contribuir em tornar o cotidiano de trabalho "um dispositivo para a estruturação, organização, estabelecimento de diretrizes e espaço de tomada de decisões" (Ferreira et al., 2019, p. 232).

O conceito de saúde implicado é referido pela literatura analisada como uma noção ampliada, visto que a ausência de doenças e o simples acesso aos serviços não seriam suficientes para garantir tal condição. Assim, tem-se o entendimento da saúde como o entrecruzamento dos setores, saberes e práticas, o que requer o compartilhamento de responsabilidades sociais, incluindo a população como participante ativa deste processo (Iglesias, 2009). Nesta mesma direção, a noção de trabalho adotada pressupõe o abandono da concepção de trabalho fragmentado e individualizado, dado a partir da estratificação das categorias profissionais e tecnicismo, para uma perspectiva de integração entre os diversos atores sociais.

Verifica-se uma consonância entre as conceituações trazidas pelos artigos analisados e aquelas apresentadas pela PNEPS, o que permite afirmar certo consenso entre as concepções trazidas. O mesmo foi constatado por Stroschein e Zocche (2011) em sua análise acerca de experiências de EPS realizadas no Brasil. No que diz respeito às concepções, as autoras também observam um destaque da aprendizagem significativa como pressuposto para EPS, acrescido da pedagogia da problematização. Pontuam que a troca de saberes entre profissionais e usuários, bem como a aplicabilidade desses conhecimentos no processo de trabalho, asseguram a aprendizagem significativa e refletem mudanças nos modelos de atenção e nas práticas em saúde 
(Stroschein \& Zacche, 2011).

Diferentemente, Ferreira et al. (2019) e Campos, Sena e Silva (2017) analisam que as concepções de EPS observadas em seus estudos apresentavam certa ambiguidade em relação aos pressupostos teóricos. De um lado algumas concepções sugerem o embasamento em conceitos críticos e pautados na pedagogia problematizadora e em oposição a isso, outras relacionam-se com modalidades educativas tradicionais.

A aproximação das conceituações apreendidas neste estudo à PNEPS, entretanto, não significa assumir, conforme trazidos pelos artigos analisados, uma ampla apreensão de seu conceito pelos trabalhadores, tampouco que exista uma definição unânime entre os trabalhos que tratam sobre EPS, em razão dos diversos aspectos envolvidos nesta modalidade educativa: formação dos trabalhadores, mudanças nas práticas de trabalho, aproximação com a comunidade e instituições de ensino, gestão participativa, partilha de responsabilidades, postura reflexiva e críticas, entre outros. Apesar disso, foi possível constatar aspectos comuns a todas concepções, como o caráter emancipatório e coletivo, a articulação com a realidade social, a contribuição na formação profissional e a mudança institucional suscitada.

Foi possível apreender também, a partir dos artigos analisados, certa fragilidade em relação ao fazer cotidiano da PNEPS, expressa na dificuldade dos profissionais em reconhecer os problemas cotidianos e da mesma forma caracterizar ações e práticas que refletem a EPS. Campos, Sena e Silva (2017) alertam para a importância de estudos que se aprofundem na EPS, tendo como referência o cotidiano dos serviços de saúde, de forma a potencializar os processos de efetivação da EPS.

As atividades mais citadas pela literatura científica, como viabilizadoras da EPS são: reuniões de equipe, momentos de discussão de casos, atendimento compartilhado, grupos e ações voltadas para comunidade (Lima et al., 2010). Foram identificadas que formações realizadas a partir da pedagogia problematizadora contribuíram para a "ampliação do olhar sobre a prática de trabalho e potencialidades da Educação Permanente em Saúde" (Campos, Sena \& Silva, 2017, p. 4).

Lamante et al. (2019) ao investigarem as concepções de EPS em uma equipe multiprofissional, indicam que os profissionais analisam o processo de EPS como um instrumento de reflexão que os permitiu apreender a importância de questionar os processos de trabalho e cuidado em saúde; necessário para promover a otimização dos processos de trabalho e a qualidade nos serviços de saúde prestados. As mudanças observadas no ambiente de trabalho, na perspectiva dos trabalhadores, parecem relacionadas à possibilidade de compartilhar os problemas no grupo e, assim, se co-responsabilizam pelas tomadas de decisões e resultados.

Todavia, também compareceu nesta revisão a dificuldade dos profissionais de saúde se apropriarem dessa lógica formativa trazida pela EPS, que os convoca a participarem dos processos decisórios. Associa-se nesta pesquisa essa dificuldade de apropriação pelos profissionais a outro desafio presente nos estudos: a falta de autonomia desses trabalhadores. Entende-se que essa pouca governabilidade dos trabalhadores no que se refere aos seus processos de trabalho, repercutirá na credibilidade desses atores em relação a aderirem a uma proposta que afirma sua participação nas decisões cotidianas.

É possível ainda, associar essa falta de protagonismo e autonomia por parte dos profissionais em relação às ações que refletem a EPS, à presença do modelo biomédico, fortemente incorporado às práticas de trabalho, cuidado e formação na saúde, sustentado em características centralistas, verticalistas e autoritárias na tomada de decisão (Stroschein \& Zocche, 2011; Pinto et al., 2010).

Ainda relativo às conceituações da EPS, verifica-se que as concepções analisadas refletem exclusivamente os entendimentos dos trabalhadores de saúde e instituições de ensino. De modo geral, as pesquisas não acessam as ideias e entendimentos em torno da EPS a partir da ótica dos usuários dos serviços, reduzindo o quadrilátero da formação em saúde (Ceccim \& Feuerwerker, 2004) aos profissionais, gestores e instituições formativas. No que diz respeito às ações de EPS, Lima et al. (2010) observam que apenas $24 \%$ dos profissionais realizavam atividades que envolviam o nível de controle social. De 
forma semelhante, Pinto et al. (2010) indicam uma participação de 3,5\% de usuários nos momentos de EPS promovidos no ano de 2006 no município de Vitória.

Esse distanciamento dos usuários se afirma como um obstáculo à efetivação da EPS em toda sua potencialidade. A ausência desse importante ator social na efetivação da EPS, diz também, da deficitária apreensão da conceituação da EPS, que requer necessariamente, o controle social na composição dos processos formativos que se quer para o SUS. Tratam-se de processos formativos focados na transformação das práticas técnicas e sociais, nas mudanças institucionais, na apropriação ativa do saber científico e popular por profissionais, usuários e gestores, por meio da integração desses atores (Sardinha Peixoto et. al., 2013).

Em estudo acerca da experiência de implementação da EPS em um município do Estado de São Paulo, Carotta, Kawamura e Salazar (2009) salientam justamente, como uma das principais dificuldades encontradas, a aplicação dos conceitos relativos a EPS no cotidiano, acrescido, da ampliação da participação dos usuários, inclusão dos médicos nas discussões da política, desmotivação dos profissionais e impasses na realização de encontros e ações para aprofundamento nas questões suscitadas no trabalho em saúde.

Neste caminho, como trazido nos resultados dessa revisão, compareceu certa dificuldade dos atores da saúde em agregar propostas e ações diferentes das modalidades educativas tradicionais, tanto que a EC ainda é tomada como sinônimo de EPS, e essa última preterida à primeira. Outros estudos (Ferreira et al., 2019; Campos, Sena \& Silva, 2017; Figueredo et al., 2014) retratam uma associação entre EPS e EC, o que pode ser justificado pela adoção de muitos termos para referir-se aos processos ensino-aprendizagem envolvidos no trabalho em saúde (educação em saúde, educação na saúde, educação interprofissional, EPS, EC). Figueredo et al. (2014) apontam que mesmo sendo comum aos trabalhadores da saúde confundir as modalidades educativas, suas diferenças podem ser assimiladas nas publicações do Ministério de Saúde e nas literaturas específicas de cada uma.

A EC surge como uma proposta educativa pensada para a atualização da formação básica e profissional. Essa proposta se relaciona, principalmente, ao aprimoramento de um ofício ou capacitação de trabalhadores em decorrência de novas atividades e demandas de trabalho. Nesse contexto, a EC caracterizou-se pelo desenvolvimento de grupos e qualificações profissionais, centradas em métodos educacionais tradicionais, pautados na transmissão de conhecimentos técnicos (Falkenberg et al., 2014).

Em contrapartida, a EPS consiste em ações educativas embasadas na problematização do processo de trabalho em saúde, com o intuito de produzir mudanças na organização do trabalho e nas práticas profissionais nesse campo. Nessa abordagem, também adota-se a concepção de educação ao longo da vida, ao buscar reconhecer os saberes produzidos a partir da experiência, assumindo o potencial de qualquer indivíduo em produzir conhecimento. Prioriza-se espaços de reflexões e construção coletiva do conhecimento, destacando enquanto protagonistas todos os atores envolvidos no fazer cotidiano da saúde (Brasil, 2018).

Os impasses apresentados na operacionalização da EPS, de acordo com os artigos analisados, aparecem associados a diferentes ordens: dificuldades institucionais, como a falta de financiamento e a rotatividade dos profissionais em conformidade com a mudança de gestão e natureza dos vínculos empregatícios; impasses relacionais, a exemplo da falta de comunicação e comprometimento com as mudanças; desafios decorrentes do processo de trabalho e da formação em saúde no Brasil, a exemplo a resistência enfrentada na superação do modelo biomédico, o excesso de demandas indicadas pelos trabalhadores, a falta de protagonismo na construção da Educação Permanente em Saúde, bem como as noções vagas e desalinhadas acerca da EPS.

No que concerne ao financiamento da PNEPS, é importante destacar que a proposta instituída em 2004, previa um repasse permanente e descentralizado dos recursos financeiros, nesse sentido, cada entidade federativa seria responsável pela gestão, planejamento e execução de seus projetos educativos e de gestão do trabalho. Outro ponto relevante foi a distribuição dos recursos de modo a favorecer as regiões com menor capacidade e estrutura disponíveis para o desenvolvimento das ações de EPS (Bravin, 2008). 
A partir de 2006, os recursos federais destinados à educação na saúde passaram a ser divididos entre a Educação Profissional de Nível Técnico e EPS. Essa separação implicava em duas possíveis reflexões: de um lado colocava-se uma preocupação em fragmentar a participação dos atores da saúde no trabalho com a EPS e de outro, a possibilidade dessa condição incentivar uma maior participação dos profissionais de nível médio, em função de um maior envolvimento dos trabalhadores com formação de nível superior (Stroschein \& Zocche, 2011). De modo parecido, Pinto et al. (2010) em sua pesquisa ressaltam uma maior participação de profissionais com nível superior nos momentos de EPS, sendo eles "os que mais se manifestam, são mais ouvidos e se responsabilizam por grande parte das tarefas" (p.89), o que certamente implica em prejuízo a proposta teórica da EPS de transversalização das relações no campo da saúde.

Bravin (2008) aponta ainda que gestores municipais e federais percebiam uma incompatibilidade entre a distribuição de recursos direcionados às ações educativas proposta pela portaria. Em 2011, então, aconteceu uma interrupção do financiamento da PNEPS por parte do Ministério da Saúde, o que se relaciona também, à pouca priorização da EPS pelos gestores, prejudicando sua continuidade e inclusão no planejamento das agendas de trabalho, como inclusive indicado nos artigos levantados nesta pesquisa.

Conforme os estudos analisados, outro fator que influencia a continuidade das ações de EPS é a rotatividade dos profissionais de saúde, que compareceu relacionada a dois principais motivos. O primeiro relaciona-se com a natureza dos vínculos empregatícios, visto que grande parte dos profissionais atua no regime de contratação temporária em desproporção com o número de profissionais efetivos (Ferreira et al., 2019; Pinto et al., 2010). O segundo fator relaciona-se com a mudança nos cargos de gestão na saúde, que acompanha as trocas de gestão dos municípios, estados e união (Lima et al., 2010). "Esta descontinuidade faz com que os serviços estejam sempre reiniciando, e os profissionais dos serviços de saúde colocando-se em uma posição de espectadores e não de agentes proativos" (Lima et al. 2010, p. 222).

Em Pinto et al. (2010) comparecem expressivamente como desafios a serem superados: a falta de suporte e protagonismo dos profissionais na realização de atividades de EPS. As autoras observam diferentes graus de motivação e participação entre os profissionais para as rodas de EPS realizadas no município pesquisado, destacando-se aqueles trabalhadores que de fato se envolviam com a proposta; os que almejavam descansar de suas rotinas de trabalho e outros que participavam pela imposição da gerência. Essa dinâmica mostrou-se prejudicial para continuidade dessas atividades, visto que apenas um pequeno grupo de profissionais responsabilizava-se pela proposta. Por outro lado, entende-se que essa pouca participação desses trabalhadores pode se relacionar com a falta de certas condições de trabalho, como a própria sobrecarrega apontada nos artigos, ou ainda com o descrédito gerado nos profissionais pela descontinuidade das proposta desse sistema de saúde, de integração e compartilhamento de decisões, suscitadas também, pela EPS.

Assim como encontrado neste estudo, comparecem na revisão realizada por Ferreira et al. (2019), como fragilidades na realização de iniciativas de EPS: a sobrecarga de trabalho, a falta de planejamento das ações e o reconhecimento de pouca valorização da EPS por parte dos gestores. Adicionado a isso, Campos, Sena e Silva (2017), identificam: distanciamento entre as instituições de ensino e serviços de saúde, dificuldade na democratização dos espaços de trabalho e na construção de um senso de corresponsabilização entre os trabalhadores, evidenciando impasses também verificados por esta revisão. Assim, destaca-se a importância do alinhamento entre as instituições de ensino, serviços de saúde e comunidades para o sucesso das ações de EPS. Torna-se imprescindível que as reflexões produzidas incluam, para além das práticas em saúde, como tem operado a formação em saúde no Brasil e quais concepções de educação presentificam-se nesses processos.

Dentre as potencialidades apresentadas no corpus de análise dessa revisão estão: a transformação das práticas e realidades de trabalho; melhoria na qualidade dos serviços, da gestão e das condições de trabalho; desenvolvimento de autonomia e fomento de espaços democráticos; maior integração profissional e desenvolvimento de habilidades técnicas e relacionais; 
mudanças na formação em saúde de modo geral ao promover maior proximidade entre ensino-serviço-comunidade; construção de conhecimentos e vontades coletivas; mudanças nas concepções de saúde e modelo de assistência e fortalecimento do SUS.

Em pesquisa realizada por Lima et al. (2010), identificou-se que 70,2\% dos participantes afirmaram perceber mudanças desencadeadas pela EPS nas realidades de trabalho, sendo que 44,2\% destes profissionais acreditam tratar-se de mudanças parciais, relacionadas principalmente com uma maior integração profissional (84,9\%), aumento do acolhimento e humanização nas práticas de saúde $(83,6 \%)$, maior democratização da gestão $(77,3 \%)$ e conhecimento acerca das demandas em saúde da comunidade (60,3\%). Na visão dos trabalhadores, a EPS viabilizou a construção de espaços democráticos e coletivos para debates, disparando processos de mudança tanto na gestão como no cuidado em saúde. Outras pesquisas evidenciam que o processo de EPS contribui para uma gestão participativa (Lamante et al. 2019; Campos, Sena \& Silva, 2017; Pinto et al., 2010; Carotta, Kawamura \& Salazar, 2009).

A atitude reflexiva aparece como aspecto importante a ser exercitado no cotidiano dos serviços, de forma a contribuir com o reconhecimento dos problemas que presentificam-se no dia a dia. Nesse sentido, a EPS possibilita ao trabalhador aprimorar essa habilidade, funcionando também como uma ferramenta de mudanças atitudinais. Ademais permite que os trabalhadores desenvolvam maior segurança em relação às suas práticas, e principalmente colabora para uma maior apropriação dos profissionais de seus processos de trabalho, produzindo valorização entre os sujeitos implicados na EPS (Lamante et al. 2019).

Corroborando com esses achados, Ferreira et al. (2019) destacam entre os pontos positivos da efetivação da PNEPS, a ressignificação das práticas em saúde e a inter-relação entre ensino-serviço. Igualmente, Stroschein e Zocche (2011, p. 510) apontam os "acordos coletivos, ações estratégicas em saúde, protagonismo, transformação das práticas de atenção, de gestão e controle social e produção políticas enraizadas nos princípios e nas diretrizes do SUS”. No mesmo sentido, Lima et al. (2010) indicam a construção coletiva e composição multiprofissional das equipes como potencializadoras de mudanças nos processos de saúde e trabalho, o que também é observado a partir dos artigos analisados nesta revisão.

Carotta, Kawamura e Salazar (2009) assinalam como facilidades encontradas para implementação da PNEPS, a priorização da EPS e comprometimento por parte da gestão; apoio e legitimação das reuniões e rodas de reflexão; possibilidade em propor ações e estratégias em conformidade com as demandas em saúde dos usuários; e por fim, a implicação dos facilitadores e demais profissionais no processo. Esses achados permitem reafirmar as especificidades que o trabalho com EPS pode assumir nas diferentes regiões e experiências.

\section{Considerações Finais}

Este estudo buscou conhecer como tem sido abordada a temática da Educação Permanente em Saúde na literatura científica, de forma a apreender os principais entendimentos, dificuldades e potencialidades decorrentes do trabalho com a EPS. Nesse sentido, percebe-se uma aproximação entre os entendimentos acerca da EPS observados nesta revisão e as concepções expressas nas publicações do Ministério da Saúde relativas à temática. No entanto, como trazido pelos artigos analisados, na prática, compareceu certa dificuldade dos profissionais em distinguirem as noções de EC e EPS, o que contribui para limitar as ações de EPS à espaços caracterizados pela transmissão de informações.

Nota-se ainda, que as concepções trazidas pelos artigos analisados são provenientes dos trabalhadores da saúde, gestores e instituições de ensino, envolvidas com a produção científica. Não sendo possível conhecer como a EPS tem sido experienciada pelos usuários e quais os entendimentos dessa proposta são produzidos por eles. De modo parecido, observa-se pouca participação dos usuários nas ações caracterizadas como práticas de EPS. Nesse sentido, ratifica-se a necessidade de investigação de tal afastamento.

No que diz respeito aos impasses enfrentados no fazer cotidiano da PNEPS, são apontadas dificuldades institucionais, 
relacionadas aos processos de trabalho e ao modo como tem ocorrido a formação profissional em saúde no Brasil. Evidencia-se a interrupção do financiamento da PNEPS como um dos maiores impasses para institucionalização da EPS. Adiciona-se a isso a falta de envolvimento dos profissionais e gestores; uma assistência à saúde fragmentada; e o desalinhamento das concepções de EPS.

Verifica-se uma relação estabelecida entre os aspectos destacados como impasses e a presença do modelo biomédico, incorporado nas práticas de trabalho, cuidado em saúde, gestão dos serviços e formação em saúde. Nesse sentido, para que o rompimento com essa realidade seja efetivo, para além das intervenções nos dispositivos de saúde, torna-se urgente reflexões e mudanças de práticas nas instituições de ensino em saúde e suas práticas e metodologias educativas.

Dentre as potencialidade decorrentes da EPS sobressaem as mudanças alcançadas em relação a organização do trabalho; uma gestão mais participativa com vista ao desenvolvimento de autonomia por parte dos trabalhadores; o incremento nas habilidades técnicas e relacionais; e por fim, a mudança nas concepções de saúde e no modelo de assistência.

Verificou-se um número maior de estudos que discutem os entendimentos, bem como as dificuldades colocadas nas práticas da EPS, em comparação com estudos que destacam as potencialidades. Por isso, ressalta-se a importância de trabalhos que explorem as potencialidades na efetivação da EPS, de forma a contribuir com a disseminação dos avanços e possibilidades alcançadas no trabalho na saúde. Acredita-se que ao evidenciar os aspectos positivos e resultados obtidos, incentiva-se a promoção de experiências e ações que denotem a Educação Permanente em Saúde.

\section{Referências}

Bispo, J. P. J. \& Moreira, D. C. (2017). Educação permanente e apoio matricial: formação, vivências e práticas dos profissionais dos Núcleos de Apoio à Saúde da Família e das equipes apoiadas. Cadernos de Saúde Pública, 33(9), 1-13. doi: 10.1590/0102-311X00108116

Brasil. Ministério da Saúde. Secretaria de Gestão do Trabalho e Educação na Saúde. (2009). Glossário Temático: gestão do trabalho e educação na saúde. Brasília: Ministério da Saúde.

Brasil. Ministério da Saúde. Secretaria de Gestão do Trabalho e Educação na Saúde. (2018). Política Nacional de Educação Permanente em Saúde: o que se tem produzido para seu fortalecimento?. Brasília: Ministério da Saúde.

Bravin, F. P. (2008). Política e ação pública: análise da política nacional de Educação Permanente em Saúde. (Dissertação de mestrado). Universidade de Brasília, Brasília.

Campos, K. F C., Sena, R. R. \& Silva, K. L. (2017). Educação permanente nos serviços de saúde. Escola Anna Nery, 21(4), 1-10. doi: 10.1590/2177-9465-ean2016-0317

Cardoso, M. L. M., Costa, P. P., Costa, D. M., Xavier, C. \& Souza, R. M. P. (2017). A Política Nacional de Educação Permanente em Saúde nas Escolas de Saúde Pública: reflexões a partir da prática. Ciência \& Saúde Coletiva, 22(5), 1489-1500. doi: 10.1590/1413-81232017225.33222016

Carotta, F., Kawamura, D. \& Salazar, J. (2009). Educação permanente em saúde: uma estratégia de gestão para pensar, refletir e construir práticas educativas e processos de trabalhos. Saúde e Sociedade, 18(1), 48-51. doi: 10.1590/S0104-12902009000500008

Ceccim, R. B. (2005). Educação Permanente em Saúde: descentralização e disseminação de capacidade pedagógica na saúde. Ciência \& Saúde Coletiva, 10(4), 975-986. doi: 10.1590/S1413-81232005000400020

Ceccim, R. B. \& Feuerwerker, L. (2004). O quadrilátero da formação para a área da saúde: ensino, gestão, atenção e controle social. Physis - Rev. Saúde Coletiva, 14(1), 41-65. https://www.scielo.br/j/physis/a/GtNSGFwY4hzh9G9cGgDjqMp/?lang=pt\&format=pdf

Diniz, D. S. \& Sá, M. C. (2019). O uso de narrativas e do dispositivo grupal na formação/educação permanente dos profissionais de saúde: uma revisão de literatura. Interface (Botucatu), 23(1), 1-18. doi: 10.1590/Interface.180217

Ferreira, L., Barbosa, J. S. A., Esposti, C. D. D. \& Cruz, M. M. (2019). Educação Permanente em Saúde na atenção primária: uma revisão integrativa da literatura. Saúde em Debate, 43(120), 223-239. doi: 10.1590/0103-1104201912017

Falkenberg, M. B., Mendes, T. P. L., Moraes, E. P. \& Souza, E. M. (2014). Educação em saúde e educação na saúde: conceitos e implicações para a saúde coletiva. Ciência e Saúde Coletiva, 19(3), 847-852. doi: 10.1590/1413-81232014193.01572013

Figueiredo, E. B. L., Gouvêa, M. V., Cortez, E. A., Santos, S. C. P., Alóchio, K. V. \& Alves, L. M. S. (2017). Dez anos da educação permanente como política de formação em saúde no Brasil: um estudo das teses e dissertações. Trabalho, Educação e Saúde, 15(1), 147-162. doi: 10.1590/1981-7746-sol00036. 
Figueredo, R. C., Celestino, K. A. A., Moraes, C. R. F. \& Figueiredo, I. I S. (2014). Desafios e Perspectivas na Educação Permanente em Saúde desenvolvida na Atenção Primária: uma revisão bibliográfica. Revista Científica do ITPAC, 7(4), 1-7. http://nephrp.com.br/site/wp-content/uploads/2017/03/Desafios-ePerspectivas-na-Educa\%C3\%A7\%C3\%A3o-Permanente-em-sa\%C3\%BAde-desenvolvida-na-aten\%C3\%A7\%C3\%A3o-prim\%C3\%A1ria-umarevis\%C3\%A3o-bibliogr\%C3\%A1fica.pdf

França, T., Medeiros, K. R., Belisario, S. A., Garcia, A. C., Pinto, I. C. M., Castro, J. L. \& Pierantoni, C. R. (2017) Política de Educação Permanente em Saúde no Brasil: a contribuição das Comissões Permanentes de Integração Ensino-Serviço. Ciência \& Saúde Coletiva, 22(6), 1817-1828. doi: 10.1590/141381232017226.30272016

Gigante, R. L. \& Campos, G. W. S. C. (2016). Política de formação e educação permanente em saúde no Brasil: bases legais e referências teóricas. Trabalho, Educação e Saúde, 14(3), 747-763. doi: 10.1590/1981-7746-sip00124

Iglesias, A. (2009). Em nome da promoção à saúde: análise das ações em unidade de saúde da macrorregião de Maruípe, Vitória -ES (Dissertação de Mestrado). Universidade Federal do Espírito Santo, Vitória, ES.

Lamante, M. P. S., Chirelli, M. Q., Pio, D. A. M., Tonhom, S. F. R. \& Corrêa, M. E. S. H. (2019). A Educação Permanente e as Práticas em Saúde: concepções de uma equipe multiprofissional. Revista Pesquisa Qualitativa, 7(14), 230-244. doi: 10.33361/RPQ.2019.v.7.n.14.268

Leite, C. M., Pinto, I. C. M. \& Fagundes, T. L. Q. (2020). Educação Permanente em Saúde: reprodução ou contra-hegemonia?. Trabalho, Educação e Saúde, 18(1), 1-15. doi: 10.1590/1981-7746-sol00250.

Lima, J. V. C., Turini, B., Carvalho, B. G., Nunes, E. F. P. A., Lepre, R. L., Mainard, P. \& Cordoni Junior, L. (2010). A Educação Permanente em Saúde como estratégia pedagógica de transformação das práticas: possibilidades e limites. Trabalho, Educação e Saúde, 8(2), 207-227. doi: 10.1590/S198177462010000200003

Lima, S. A. V., Alburquerque, P. C. \& Wenceslau, L. D. (2014). Educação permanente em saúde segundo os profissionais da gestão de Recife, Pernambuco. Trabalho, Educação e Saúde, 12(2), 425-441. doi: 10.1590/S1981-77462014000200012

Mendonça, F. F. \& Nunes, E. F.P. A. (2011). Necessidades e dificuldades de tutores e facilitadores para implementar a política de educação permanente em saúde em um município de grande porteno estado do Paraná, Brasil. Interface (Botucatu), 15(38), 871-882. doi: 10.1590/S1414-32832011000300020

Miccas, F. L. \& Batista, S. H. S. S. (2014). Educação permanente em saúde: metassíntese. Revista de Saúde Pública, 48(1), 170-185. doi: 10.1590/S00348910.2014048004498

Minayo, Maria Cecilia de Souza. (2004). O desafio do conhecimento: pesquisa qualitativa em saúde (8 ed.). São Paulo: Hucitec.

Mishima, S. M., Aiub, A. C., Rigato, A. F. G., Fortuna, C. M., Matumoto, S., Ogata, M. N., ... Nogueira, A. C. (2015). Perspectiva dos gestores de uma região do estado de São Paulo sobre educação permanente em saúde. Revista Escola de Enfermagem USP, 49(2), 665-673. doi: 10.1590/S0080-623420150000400018

Morosini, M. V., Fonseca, A. P. \& Pereira, I. B. Educação em Saúde. (2008). In: Pereira, I. B.; \& Lima, J. C. F. (Orgs.). Dicionário da educação profissional em saúde. (pp. 207-223). Rio de Janeiro, RJ: EPSJV

Nicoletto, S. C. S., Bueno, V. L. R. C., Nunes, E. F. P. A., Cordoni, L. J., González, A. D., Mendonça, F. F., ... Carvalho, G. S. (2013) Desafios na implantação, desenvolvimento e sustentabilidade da Política de Educação Permanente em Saúde no Paraná, Brasil. Saúde e Sociedade, 22(4), 1094-1105. doi: 10.1590/S010412902013000400012

Nogueira, I. S., Acioli, S., Carreira, L. \& Baldissera, V. D. A. (2019). Atenção ao idoso: práticas de educação permanente do Núcleo de Apoio à Saúde da Família. Revista Escola de Enfermagem USP, 53(1), 1-9. doi: 10.1590/S1980-220X2018022103512

Peres, C., Silva, R. F. \& Barba, P. C. S. D. (2016). Desafios e potencialidades do processo de educação permanente em saúde. Trabalho, Educação e Saúde, 14(03), 783-801. doi: 10.1590/1981-7746-sol00016.

Pinto, E. E. P., Araújo, M. D., Matumoto, S., Capozzolo, A. A., Cardoso, M. R. L. \& Mishima, S. M. (2010). Desdobramentos da educação permanente em saúde no município de Vitória, Espírito santo. Trabalho, Educação e Saúde, 8(1), 77-96. doi: 10.1590/\$1981-77462010000100005

Sardinha Peixoto, L., Cuzatis Gonçalves, L., Dutra Da Costa, T., Tavares, C. M. M., Dantas Cavalcanti, A. C. \& Antunes Cortez, E.. (2013). Educação permanente, continuada e em serviço: desvendando seus conceitos. Enfermería Global, 12(29), 307-322. http://scielo.isciii.es/scielo.php?script=sci_arttext\&pid=S1695-61412013000100017\&lng=es\&tlng=pt.

Sena, R. R., Grillo, M. J. C., Pereira, L. d'A., Belga, S. M. M. F., França, B. D. \& Freitas, C. P. (2017). Educação permanente nos serviços de saúde: atividades educativas desenvolvidas no estado de Minas Gerais, Brasil. Revista Gaúcha de Enfermagem, 38(2), 1-7. doi: 10.1590/1983-1447.2017.02.64031

Silva, C. B. G. \& Scherer, M. D. A. (2020). A implementação da Política Nacional de Educação Permanente em Saúde na visão dos atores que a constroem. Interface (Botucatu), 24(1), 1-15. doi: 10.1590/Interface.190840

Silva, L. A. A., Leite, M. T. \& Pinno, C. (2014) Contribuições da comissões de integração ensino-serviço na educação permanente em saúde. Trabalho, Educação e Saúde, 12(2), 403-424. doi: 10.1590/S1981-77462014000200011

Silva, L. A. A., Soder, R. M., Petry, L. \& Oliveira, I. C. (2017). Educação permanente em saúde na atenção básica: percepção dos gestores municipais de saúde. Revista Gaúcha de Enfermagem, 38(1), 1-8. doi: 10.1590/1983-1447.2017.01.58779

Silva, L. A. A., Schmidt, S. M. S., Noal, H. C., Signor, E. \& Gomes, I. E. M. (2016) Avaliação da educação permanente no processo de trabalho em saúde. Trabalho, Educação e Saúde, 14(3), 765-781. doi: 10.1590/1981-7746-sol00015 
Research, Society and Development, v. 10, n. 14, e355101422015, 2021

(CC BY 4.0) | ISSN 2525-3409 | DOI: http://dx.doi.org/10.33448/rsd-v10i14.22015

Souza, M. T., Silva, M. D. \& Carvalho, R. (2010). Revisão Integrativa: o que é e como fazer. Einstein (São Paulo), 8(1), p. 102-106. doi: 10.1590/S167945082010RW1134

Souza, C. Z., Anton, L. A. \& Oliveira, M. C. S. L. (2019). Educação permanente em saúde e desenvolvimento adulto: a experiência das oficinas fotográficas de sensibilização do olhar. Gerais: Revista Interinstitucional de Psicologia, 12(2), 338-355. https://pesquisa.bvsalud.org/portal/resource/pt/biblio-1006230

Stroschein, K. A. \& Zocche, D. A. A. (2011). Educação permanente nos serviços de saúde: um estudo sobre as experiências realizadas no Brasil. Trabalho, Educação e Saúde, 9(3), 505-519. doi: 10.1590/S1981-77462011000300009

Yamamoto, T. S., Machado, M. T. C. \& Silva, A. G. J. (2015). Educação permanente em saúde como prática avaliativa amistosa à integralidade em Teresópolis, Rio de Janeiro. Trabalho, Educação e Saúde, 13(3), 617-637. doi: 10.1590/1981-7746-sip00058 